\title{
Condicionamento fisiológico na germinação e no vigor de sementes armazenadas de café
}

\author{
Stored coffee seeds germination and vigour as affected by physiological conditioning
}

\author{
Madelon Rodrigues Sá Braz ${ }^{\mathrm{I}}$ Claudia Antonia Vieira Rossetto ${ }^{\mathrm{II}}$
}

\section{RESUMO}

O objetivo do trabalho foi avaliar o efeito do condicionamento fisiológico na germinação e no vigor de sementes armazenadas de café. Para tanto, as sementes de café da cultivar "Catuaí Vermelho IAC 144" foram secas até atingir $30 \%$ de água e expostas a quatro condições de conservação: combinação de dois materiais de embalagens (polietileno e algodão) e de dois ambientes de armazenamento (câmara seca e ambiente sem controle de temperatura e umidade relativa do ar). Após zero, três, seis e nove meses de armazenamento, as sementes foram submetidas ao condicionamento fisiológico, empregando-se a técnica de exposição em câmara com atmosfera saturada $e$ a de condicionamento osmótico com PEG 6000 a 0,0 e a -0,4MPa. Sementes não-condicionadas foram usadas como controle. As sementes foram submetidas à determinação do teor de água e aos testes de germinação, de vigor e de sanidade. $O$ condicionamento fisiológico favoreceu a germinação $e$ o vigor das sementes de café armazenadas em embalagem de polietileno e em câmara seca, durante nove meses.

Palavras-chave: Coffea arabica L., embalagem, hidratação, envigoramento.

\section{ABSTRACT}

The objective of this research was to evaluate the effect of priming on stored coffee seeds germination and vigour. The coffee seeds, cv. 'Catuaí Vermelho IAC 144' were dried at $30 \%$ of moisture content and exposed to four storage conditions combined with two packing materials (polyethylene and cotton) and two storage environments (dry chamber and uncontrolled environment). After each storage period (zero, three, six and nine months), the seeds were submitted to priming treatments by saturated atmosphere or osmotic conditioning with PEG 6000 at 0.0 and -0.4MPa. Unprimed seeds were used as control.
The seeds were evaluated by tests of moisture content, germination, vigour and health test. The physiological conditioning favored the seeds germination and vigour that were stored in the polyethylene packs and maintained in the dry chamber, during nine months.

Key words: Coffea arabica L., packing, hydration, invigoration.

\section{INTRODUÇÃO}

A secagem e o armazenamento são, possivelmente, os fatores mais importantes na preservação da viabilidade das sementes de café (Coffea arabica L.) e, conseqüentemente, na obtenção de mudas com desenvolvimento satisfatório. Assim, durante o armazenamento, um dos aspectos a serem considerados para manutenção da viabilidade é o teor inicial de água das sementes. Para GENTIL et al. (2001), sementes com teor inicial de água de 10\% apresentam menor deterioração, independente dos outros fatores envolvidos, como a temperatura ( $\mathrm{T}$ ) e a umidade relativa (UR) do ar. Porém, independente do teor de água considerado, a redução da temperatura do ar tende a aumentar o período de conservação das sementes, tornando importante a diferenciação entre os efeitos decorrentes da desidratação e os de conservação.

Buscando definir o teor de água ideal para a conservação de sementes de café, encontram-se muitas divergências de resultados na literatura. Em ambiente

IPrograma de Pós-graduação em Fitotecnia, Universidade Federal Rural do Rio de Janeiro (UFRRJ), Seropédica, RJ, Brasil.

IIDepartamento de Fitotecnia, Instituto de Agronomia, UFRRJ, 23890-000, CP 74511, Seropédica, RJ, Brasil. E-mail: cavrosse@ufrrj.br. Autor para correspondência. 
sem controle da T e UR do ar, as sementes desta espécie podem ser armazenadas com $10 \%$ de água em embalagem herméticas (ARAÚJO, 1988), com 10\% e entre 30 a $40 \%$ em embalagem semipermeável (MIRANDA et al., 1993) e com 48\% em embalagem permeável (ARAÚJO, 1988), visando à manutenção da viabilidade durante nove meses. Contudo, sob $13-23^{\circ} \mathrm{C}$ e UR do ar de 50-70\%, DIAS \& BARROS (1993) constataram que sementes de café com 37\% de água, acondicionadas em embalagem de polietileno, permaneceram viáveis por até 11 meses, quando apresentavam 22\% de água.

Além disso, devido às sementes de café apresentarem germinação lenta e desuniforme, alguns tratamentos pré-germinativos têm sido empregados envolvendo o controle da absorção de água para a realização dos processos metabólicos (SGUAREZI et al., 2001a). Em sementes desta espécie recém-colhidas, foi constatada rápida e uniforme germinação, após a exposição em câmara com atmosfera saturada durante 34 a 55 horas (SGUAREZI et al., 2001b) e a imersão em água durante oito a 12 dias sob 15 e $25^{\circ} \mathrm{C}$ (LIMA et al., 2004). No entanto, também foi verificado que o condicionamento osmótico a -0,5, -1,0 e -1,5MPa (SGUAREZI et al., 2001a) e a imersão em água durante seis dias a $20^{\circ} \mathrm{C}$ (MARANA \& MIGLIORANZA, 2005) não favoreceram a qualidade fisiológica das sementes. Além disso, em sementes desta espécie que perderam o vigor durante o armazenamento, LIMA et al. (2003) verificaram que a imersão em água durante 34 horas aumentou em $41 \%$ a germinação das sementes armazenadas por 90 dias. MOTTA (2001) também observou que houve recuperação da viabilidade das sementes que estavam armazenadas por 12 meses em condição ambiente, após dois dias de hidratação.

Diante destas considerações, o objetivo deste trabalho foi avaliar o efeito do condicionamento fisiológico na germinação e no vigor das sementes armazenadas de café, de modo que se possa analisar a eficiência de diferentes tratamentos pré-germinativos, que envolvem o controle de absorção de água na manutenção da capacidade germinativa das sementes sob distintas condições de armazenamento, associando tipos de embalagens e de ambientes.

\section{MATERIAL E MÉTODOS}

Foi utilizado um lote de sementes de café (Coffea arabica L.) da cultivar "Catuaí Vermelho IAC 144”. Os frutos foram colhidos manualmente no estádio cereja e as sementes foram degomadas por fermentação natural. No laboratório, por ocasião do recebimento, as sementes apresentavam $45 \%$ de água e foram colocadas para secar em condições de ambiente sem controle (temperatura média do ar (T) de $23^{\circ} \mathrm{C}$ e umidade relativa do ar (UR) de 70\%), até atingirem teores próximos a 30\% de água. O delineamento experimental utilizado foi o inteiramente casualizado em esquema de parcela subsubdividida, sendo as parcelas representadas por quatro condições de conservação, as subparcelas por quatro períodos de armazenamento e as subsubparcelas por quatro técnicas de condicionamento fisiológico, com quatro repetições. Para tanto, o lote de sementes foi dividido em quatro sublotes de quatro kg, sendo que cada um foi mantido em uma condição de conservação, ou seja, 1) embalagem de algodão e em câmara seca $\left(\mathrm{T} 16 \pm 2^{\circ} \mathrm{C}\right.$ e UR50 $\pm 2 \%)$; 2) embalagem de algodão e em ambiente sem controle (T25 $\pm 3^{\circ} \mathrm{C}$ e UR64 $\pm 4 \%$ ); 3 ) embalagem de polietileno de $0,8 \mathrm{~mm}$ e em câmara seca $\left(\mathrm{T} 16 \pm 2^{\circ} \mathrm{C}\right.$ e UR50 $\pm 2 \%$ ); 4) embalagem de polietileno de $0,8 \mathrm{~mm}$ e em ambiente sem controle (T25 $\pm 3^{\circ} \mathrm{C}$ e UR64 $\pm 4 \%$ ).

Imediatamente antes e após três, seis e nove meses de armazenamento, as sementes de cada subsublote (condição de armazenamento) foram divididas em quatro amostras que foram submetidas ao condicionamento fisiológico, empregando quatro tratamentos pré-germinativos que envolvem o controle da absorção de água para a realização dos processos metabólicos das sementes sob condições impostas pelos ambientes de conservação. Para isso, as sementes foram submetidas à remoção manual do pergaminho (BRASIL, 1992) e, em seguida, ao osmocondicionamento e à exposição em câmara com atmosfera saturada. Sementes não-condicionadas foram usadas como controle. Para o osmocondicionamento, as sementes foram imersas em água destilada $(0,0 \mathrm{MPa})$ e em solução de polietilenoglicol (PEG) 6000 (-0,4MPa) durante 48 horas, sob $25^{\circ} \mathrm{C}$ (SGUAREZI et al., 2001b). Já para a técnica de exposição em câmara com atmosfera saturada, as sementes foram distribuídas sobre tela metálica fixada no interior de caixas plásticas do tipo gerbox, contendo no fundo $40 \mathrm{ml}$ de água esterilizada, visando atingir $100 \%$ de UR do ar, e foram mantidas durante 48 horas, sob $25^{\circ} \mathrm{C}$ (SGUAREZI et al., 2001a). Após os períodos de condicionamento, as sementes foram colocadas para secar em ambiente sem controle de T e UR, por uma hora.

Posteriormente, após terem sido ou não condicionadas, as sementes foram submetidas à determinação do teor de água e avaliadas quanto à germinação, ao vigor e à sanidade. A determinação do teor de água foi realizada pelo método da estufa a $105 \pm 3^{\circ} \mathrm{C}$, durante 24 horas (BRASIL, 1992), utilizando quatro subamostras de 25 sementes por tratamento. Os resultados foram expressos em porcentagem (bu). 
O teste de germinação foi realizado utilizando quatro subamostras de 25 sementes por tratamento, que foram distribuídas em papel tipo germitest, umedecido com água destilada e esterilizada, em volume equivalente a 2,5 vezes a massa do substrato seco, e mantidas a $30^{\circ} \mathrm{C}$. As avaliações foram realizadas aos 14 e 35 dias (BRASIL, 1992). Foram consideradas como plântulas normais as que apresentavam hipocótilo e raízes bem desenvolvidas, proporcionais, sadias e com comprimento total maior que três $\mathrm{cm}$. Os resultados foram expressos em porcentagem de plântulas normais. Em conjunto com este teste, foi realizado o teste de primeira contagem, considerando a porcentagem de plântulas normais aos 14 dias após a instalação (NAKAGAWA, 1999).

Também foi realizado o teste de emergência, utilizando quatro subamostras de 25 sementes por tratamento. As sementes foram distribuídas em caixas plásticas do tipo gerbox, contendo areia lavada e esterilizada, que foram mantidas a $30^{\circ} \mathrm{C}$. Os demais procedimentos foram semelhantes ao do teste de germinação.

O teste de sanidade foi realizado visando avaliar a manifestação de alguns microrganismos que estão associados à redução da germinação, durante o armazenamento sob diferentes condições de conservação. Para isso, quatro subamostras de 25 sementes foram distribuídas sobre três folhas de papel filtro, umedecidas com água destilada e esterilizada, na proporção de 2,5 vezes a massa do papel seco, em caixas plásticas do tipo gerbox. A incubação foi realizada a $20^{\circ} \mathrm{C}$, em regime alternado de 12 horas de luz (fornecida por quatro lâmpadas fluorescentes de 20W), durante sete dias, com base em BRASIL (1992). Após este período, foi realizada a identificação e a quantificação de fungos nas estruturas das sementes, com auxílio de microscópico estereoscópico. Quando necessário, foram feitas lâminas e foi usado o microscópio óptico. Foi determinada a porcentagem de cada fungo, de acordo com SINGH et al. (1992) e SILVEIRA(1995). Os resultados foram expressos em porcentagem de sementes infectadas, por gênero.

Os dados foram submetidos à análise de variância. Primeiramente, foram realizados os testes de Lilliefors e de Cochran, para verificação da normalidade de distribuição e homogeneidade das variâncias dos erros. Quando necessário, as variáveis em porcentagem foram transformadas em arc seno $(\mathrm{x} / 100)^{0,5}$, sendo que nas tabelas encontram-se os dados originais. Posteriormente, foram realizadas a análise de regressão e a comparação de médias pelo teste de Tukey a $5 \%$ de probabilidade.

\section{RESULTADOS E DISCUSSÃO}

Para os parâmetros analisados, houve interação significativa entre os três fatores considerados (período de armazenamento, condição de conservação e técnicas de condicionamento fisiológico) (Tabelas 1 a 4). As sementes de café apresentavam inicialmente $29,3 \%$ de água, quando foram submetidas às quatro condições de conservação (CC) (Tabela 1). Aos três e seis meses de armazenamento, após o emprego ou não das técnicas de condicionamento fisiológico, foi constatado que o teor de água das sementes que estavam mantidas tanto em câmara seca como em ambiente sem controle e acondicionadas em polietileno (CC3 e 4) foi superior ao das sementes sob as condições de conservação um e dois. Já aos nove meses, após o emprego ou não das técnicas de atmosfera saturada e osmocondicionamento (-0,4MPa), foi verificado que as sementes que estavam em ambiente sem controle e em embalagem de polietileno (CC4) apresentaram menor teor de água do que as que estavam em câmara seca e em embalagem de polietileno (CC3), provavelmente, devido às condições de maior T do ar. De acordo com CARVALHO \& NAKAGAWA (2000), mudança na T e UR do ar provocam constantes ajustes no teor de água das sementes, principalmente, em embalagens permeável e semipermeável.

Por ocasião do início das avaliações (período zero), a germinação das sementes de café, condicionadas ou não, foi semelhante nas diferentes condições de conservação, assim como o teor de água (Tabela 1). No entanto, após seis meses de armazenamento, as sementes condicionadas pela técnica da atmosfera saturada ou as nãocondicionadas, que estavam armazenadas em embalagens de polietileno e em câmara seca (CC3), apresentaram maior germinação, mantendo esta acima de $70 \%$, limite considerado como padrão para a comercialização (BRASIL, 1999), assim conservandose melhor do que as armazenadas sob as demais condições. Estas sementes, com elevado teor de água, apresentaram valor semelhante aos das sementes que estavam acondicionadas em embalagem de polietileno e mantidas em ambiente sem controle (CC4), indicando superioridade do desempenho das sementes à medida que há redução da $\mathrm{T}$ do ar, devido, provavelmente, a reduções na taxa de respiração e no gasto energético. GENTIL et al. (2001), também verificaram que as sementes desta espécie armazenadas a $30^{\circ} \mathrm{C}$ perderam mais rapidamente o poder germinativo mesmo com teores de água mais baixo, enquanto que a manutenção desta capacidade foi mais prolongada, mesmo com 
Tabela 1 - Dados médios em porcentagem de água e de germinação, obtidos de sementes de café que foram submetidas ao condicionamento osmótico a 0,0 e a -0,4MPa, e à atmosfera saturada (AS), bem como das não-condicionadas (NC), após o armazenamento de zero, três, seis e nove meses sob quatro condições de conservação (1- embalagem de algodão e câmara seca; 2- embalagem de algodão e ambiente sem controle; 3- embalagem de polietileno e câmara seca e 4- embalagem de polietileno e ambiente sem controle).

\begin{tabular}{|c|c|c|c|c|c|c|c|c|}
\hline & 1 & 2 & 3 & 4 & 1 & 2 & 3 & 4 \\
\hline & \multicolumn{4}{|c|}{ 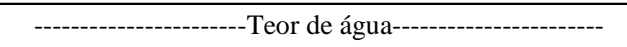 } & \multicolumn{4}{|c|}{ 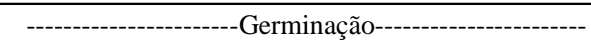 } \\
\hline & \multicolumn{8}{|c|}{ zero meses } \\
\hline$-0,4 \mathrm{MPa}$ & $45,6 \mathrm{Aa}^{1}$ & 45,6Aa & 45,6Aa & 45,6Аa & 83Аа & 83Аа & 83Aa & 83Aa \\
\hline $0,0 \mathrm{MPa}$ & 48,7Аа & 48,7Аа & 48,7Аa & 48,7Аа & 85Aa & 85Aа & 85Aa & 85Aa \\
\hline AS & $30,1 \mathrm{Ab}$ & $30,1 \mathrm{Ab}$ & $30,1 \mathrm{Ab}$ & $30,1 \mathrm{Ab}$ & 69Aа & 69Аа & 69Aа & 69Aа \\
\hline \multirow[t]{2}{*}{ NC } & $29,3 \mathrm{Ab}$ & $29,3 \mathrm{Ab}$ & $29,3 \mathrm{Ab}$ & $29,3 \mathrm{Ab}$ & 71Aa & 71Aa & 71Aa & 71Aa \\
\hline & \multicolumn{8}{|c|}{ três meses } \\
\hline$-0,4 \mathrm{MPa}$ & $42,7 \mathrm{Bb}$ & $43,6 \mathrm{Bb}$ & 47,3Ab & $46,2 \mathrm{Abb}$ & $70 \mathrm{ABa}$ & $62 \mathrm{Aa}$ & 72Aa & $62 \mathrm{Aa}$ \\
\hline $0,0 \mathrm{MPa}$ & $48,2 \mathrm{Ba}$ & 47,3Ba & 52,7Aa & 50,7Abb & $61 \mathrm{Bb}$ & 79ABa & 88Aa & $64 \mathrm{Ba}$ \\
\hline AS & $25,2 \mathrm{Bc}$ & $26,6 \mathrm{Bc}$ & 33,6Ac & $34,5 \mathrm{Ac}$ & 66Aab & 74Aa & 75Aa & 59Aa \\
\hline \multirow[t]{2}{*}{ NC } & 10,9Bd & $13,1 \mathrm{Bd}$ & 29,7Ad & 28,8Ad & 81Аa & 74Aa & 82Aa & 67Aa \\
\hline & \multicolumn{8}{|c|}{ seis meses } \\
\hline$-0,4 \mathrm{MPa}$ & 43,1Abb & $40,7 \mathrm{Bb}$ & 45,6Ab & 45,8Aa & 55Aab & $10 \mathrm{Bc}$ & 72Aa & $18 \mathrm{Bb}$ \\
\hline $0,0 \mathrm{MPa}$ & $47,0 \mathrm{Ba}$ & 49,1АВа & 51,9Аа & 49,2Aba & $64 \mathrm{Aa}$ & $11 \mathrm{Bc}$ & 78Aa & $14 \mathrm{Bb}$ \\
\hline AS & $24,7 \mathrm{Bc}$ & $25,5 \mathrm{Bc}$ & $35,4 \mathrm{Ac}$ & $34,5 \mathrm{Ab}$ & 43Bbc & $56 \mathrm{Ba}$ & 77Aa & $46 \mathrm{Ba}$ \\
\hline \multirow[t]{2}{*}{ NC } & $9,9 \mathrm{Bd}$ & $12,2 \mathrm{Bd}$ & 31,2Ad & $28,4 \mathrm{Ac}$ & $30 \mathrm{Bc}$ & $31 \mathrm{Bb}$ & 70Aa & $37 \mathrm{Ba}$ \\
\hline & \multicolumn{8}{|c|}{ nove meses } \\
\hline$-0,4 \mathrm{MPa}$ & $42,2 \mathrm{Bb}$ & $45,2 \mathrm{ABb}$ & $46,0 \mathrm{Ab}$ & $45,2 \mathrm{ABb}$ & $25 \mathrm{Ba}$ & $0 \mathrm{Ca}$ & $62 \mathrm{Aa}$ & $0 \mathrm{Ca}$ \\
\hline $0,0 \mathrm{MPa}$ & 48,3Аа & 50,8Aa & 50,5Aa & $50,7 \mathrm{Aa}$ & 29Ba & 0Ca & 71Aa & 0Ca \\
\hline AS & $25,5 \mathrm{Bc}$ & $26,8 \mathrm{Bc}$ & 33,9Ac & $28,7 \mathrm{Bc}$ & 32Ba & 0Ca & $62 \mathrm{Aa}$ & 0Сa \\
\hline \multirow[t]{2}{*}{ NC } & $10,2 \mathrm{Cd}$ & 13,2BCd & 28,6Ad & $14,4 \mathrm{Bd}$ & 19Аа & 0Ba & $21 \mathrm{Ab}$ & 0Ba \\
\hline & \multicolumn{4}{|c|}{ (condição de conservação)=4,75 } & \multicolumn{4}{|c|}{ (condição de conservação)=11,67 } \\
\hline \multirow[t]{2}{*}{$\mathrm{CV} \%$} & \multicolumn{4}{|c|}{ (período de armazenamento)=4,38 } & \multicolumn{4}{|c|}{ (período de armazenamento)=22,78 } \\
\hline & \multicolumn{4}{|c|}{ (condicionamento fisiológico) $=4,77$} & \multicolumn{4}{|c|}{ (condicionamento fisiológico)=19,05 } \\
\hline
\end{tabular}

${ }^{1}$ Médias não seguidas pela mesma letra, maiúscula na linha e minúscula na coluna,diferem entre si pelo teste Tukey a 5\% de probabilidade de erro.

teores de água elevados, sob $10^{\circ} \mathrm{C}$. Além disso, nas sementes sob a condição de conservação três, foi constatada menor incidência de Aspergillus spp. (Tabela 2), provavelmente, devido a menor $\mathrm{T}$ do ar. Resultados semelhantes foram encontrados por GENTIL et al. (2001). Estes autores observaram que, quando fixados os teores de água e os períodos de armazenamento, a redução da $\mathrm{T}$ do ar pode diminuir a ocorrência de Penicillium spp. e de Aspergillus spp. Além disso, de acordo com SGUAREZI et al. (2002), estes fungos são comuns em sementes desta espécie e estão associados à rápida diminuição da germinação.

Também a partir da tabela 1 foi constatado que somente após nove meses de armazenamento em câmara seca e embalagem de polietileno (CC3) as sementes condicionadas apresentaram maior germinação do que as não-condicionadas, sendo que apenas as que foram submetidas ao condicionamento a 0,0MPa apresentaram valor compatível ao padrão de comercialização (BRASIL, 1999). No entanto, durante a hidratação, tanto sob potencial de 0,0 como de $0,4 \mathrm{MPa}$, houve aumento do teor de água das sementes (Tabela 1). De acordo com MOTTA (2001), valores em torno de 50 a $60 \%$ são próximos daqueles requeridos para a germinação. Assim, provavelmente o aumento da concentração de PEG na solução pode ter comprometido a velocidade de absorção durante os estádios iniciais de germinação, como também constatado por SGUAREZI et al. (2001a). Além disso, após nove meses, as sementes condicionadas ou não, que estavam sob condições de conservação dois e quatro, ou seja, acondicionadas em algodão e polietileno sob ambiente sem controle, perderam completamente a viabilidade (Tabelas 1 e 2), provavelmente, devido ao teor de água alcançado no período, associado às oscilações de T e UR do ar, que interferem na taxa de respiração das sementes e deterioração de membranas, no consumo de 
Tabela 3 - Equações representativas dos dados de porcentagem de água e de germinação, obtidos em sementes de café submetidas ao condicionamento osmótico a 0,0 e a -0,4MPa, e atmosfera saturada (AS), bem como das não-condicionadas (NC), durante zero, três, seis e nove meses de armazenamento, sob quatro condições de conservação (1- embalagem de algodão e câmara seca; 2embalagem de algodão e ambiente sem controle; 3- embalagem de polietileno e câmara seca e 4- embalagem de polietileno e ambiente sem controle).

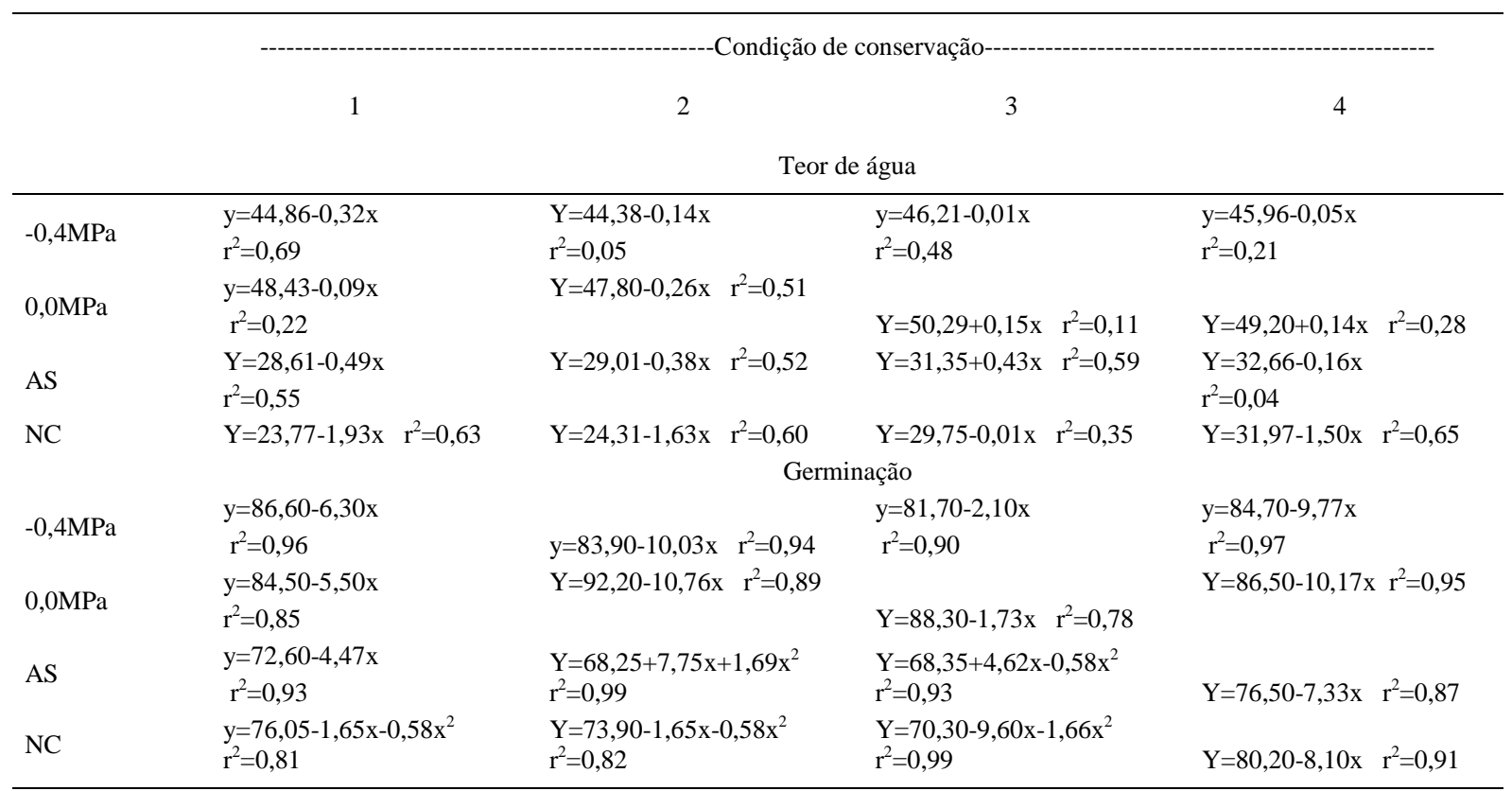

emprego ou não do condicionamento pelas técnicas de atmosfera saturada nas sementes sob C.C. três, foi constatado resultado semelhante aos obtidos nos testes de germinação (Tabela 1) e de emergência (Tabela 2), indicando que reduções da temperatura do ar de armazenamento, associadas à redução de Aspergillus spp. (Tabelas 2 e 4), conduziram à diminuição da intensidade da deterioração e, conseqüentemente, ao aumento do período de conservação das sementes. Estes resultados são semelhantes ao observados por DIAS \& BARROS (1993) e por GENTIL et al. (2001). Além disso, na tabela 2, também foi observado que, após nove meses de armazenamento, o condicionamento fisiológico favoreceu o vigor das sementes sob CC três, assim como constatado pelo teste de germinação (Tabela 1). Resultados semelhantes com o uso do condicionamento osmótico foram constatados por SGUAREZI et al. (2001a). Para BRADFORD (1986), esta técnica promove acúmulo de solutos no decorrer do processo, resultando em maior potencial de turgor celular durante a reidratação das sementes e menor período na emergência da raiz primária.

Neste trabalho, o condicionamento fisiológico aumentou a porcentagem e a velocidade de germinação das sementes que permaneceram armazenadas em embalagem de polietileno e em câmara seca. No entanto, esta técnica não pôde ser utilizada para o aprimoramento das sementes deterioradas, ou seja, que estavam armazenadas em condições sem controle, tanto na embalagem de algodão como de polietileno. Além disso, o emprego desta técnica justifica-se em função das sementes de café apresentaram reduzido potencial de armazenamento. Porém, devido aos aspectos operacionais, o emprego é limitado às empresas de sementes.

\section{CONCLUSÕES}

O condicionamento fisiológico favoreceu a germinação e o vigor das sementes de café armazenadas em embalagem de polietileno e câmara seca, durante nove meses.

\section{AGRADECIMENTO}

Ao Conselho Nacional de Desenvolvimento Científico e Tecnológico (CNPq), pela bolsa de doutorado da autora M. R. S. Braz e de produtividade em pesquisa da autora C.A.V. Rossetto.

Ciência Rural, v.38, n.7, out, 2008. 
Tabela 4 - Equações representativas dos dados de porcentagem de plântulas normais na primeira contagem de germinação, de emergência e de sementes contaminadas por Aspergillus spp., obtidos em sementes de café submetidas ao condicionamento osmótico a 0,0 e a $0,4 \mathrm{MPa}$ à atmosfera saturada (AS), bem como das não-condicionadas (NC), durante zero, três, seis e nove meses de armazenamento, sob quatro condições de conservação (1- embalagem de algodão e câmara seca; 2- embalagem de algodão e ambiente sem controle; 3- embalagem de polietileno e câmara seca e 4- embalagem de polietileno e ambiente sem controle).

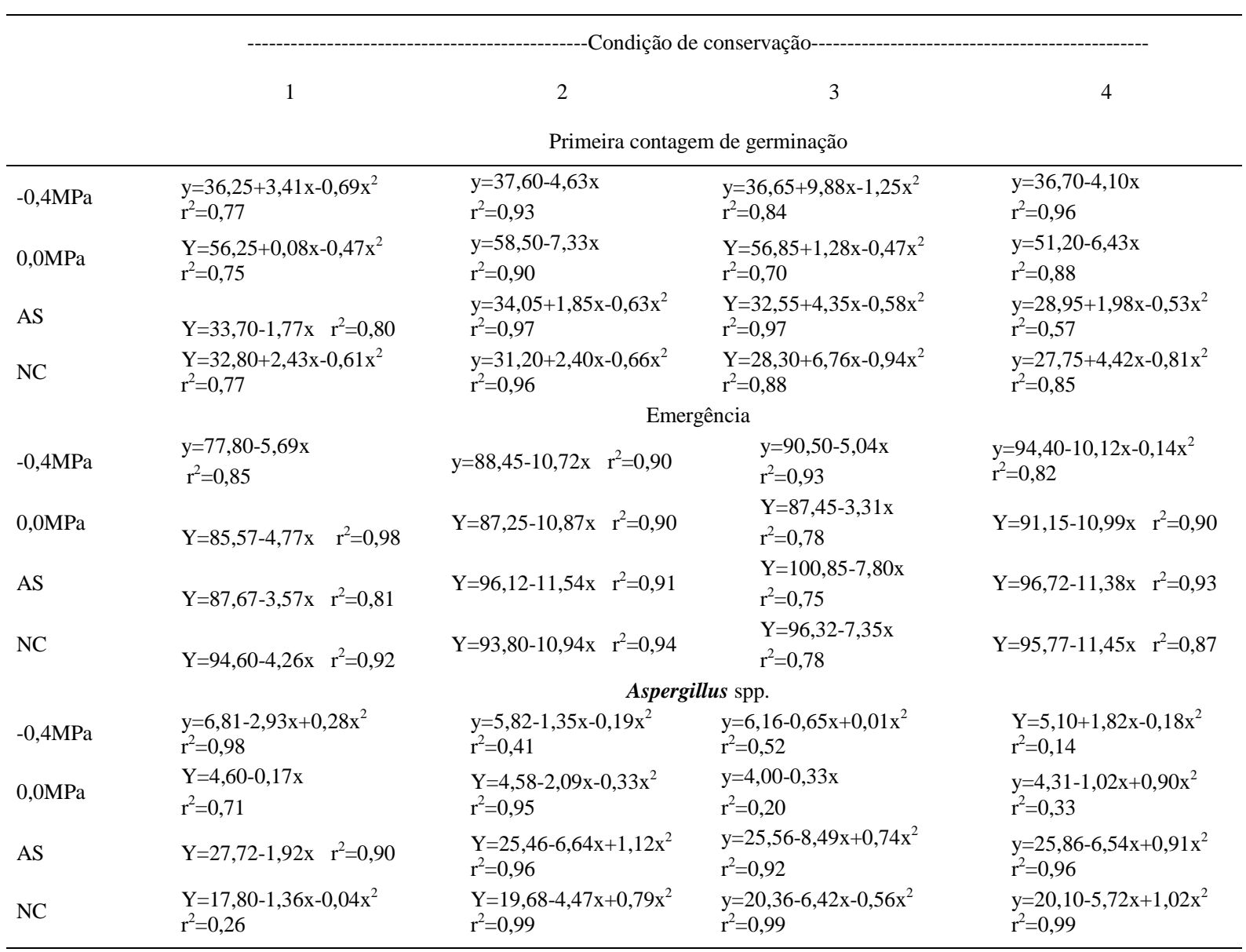

\section{REFERÊNCIAS}

ARAÚJO, R.F. Influência do teor de umidade, da embalagem e do ambiente de armazenamento na conservação de sementes de café (Coffea arabica L.). 1988. 56f. Dissertação (Mestrado em Fitotecnia) - Curso de Pósgraduação em Fitotecnia, Universidade Federal de Viçosa.

BRADFORD, K.J. Manipulation of seed water relations via osmotic priming to improve germination under stress conditions. Hort Science, Alexandria, v.21, n.5, p.1105-1112, 1986.

BRASIL. Ministério da Agricultura e da Reforma Agrária. Regras para Análise de Sementes. Brasília: SNDA / DNDV / CLAV/ MA, 1992. 365p.

BRASIL. Ministério da Agricultura. Comissão Estadual de Sementes e Mudas. Padrões de sementes para safra 99/ 2000. Campinas, 1999. Capturado em 07 jul 2004. Online. Disponível na Internet: http://www.apps.agr.br.

CARVALHO, N.M. de.; NAKAGAWA, J. Sementes: ciência, tecnologia e produção. 4.ed. Jaboticabal: Funep, 2000. 588p.
DIAS, M.C.L.L.; BARROS, A.S.R, Conservação de sementes de café em diferentes embalagens. Revista Brasileira de Sementes, Brasília, v.15, n.2, p.197-202, 1993.

GENTIL, D.F.O. et al. Grau de umidade e temperatura na conservação de sementes de café. Bragantia, Campinas, v.60, n.1, p.53-64, 2001.

LIMA, S.M.P. et al. Efeitos de tempos e temperaturas de condicionamento sobre a qualidade fisiológica de sementes de cafeeiro (Coffea arabica L.) sob condições ideais e de estresse térmico. Ciência e Agrotecnologia, Lavras, v.28, n.3, p.505514, 2004.

LIMA, W.A.A. et al. Controlled hydration for priming in coffee (Coffea arabica L.) seeds. Seed Science and Technology, Zurich, v.31, n.1, p. 29-37, 2003.

MARANA, J.P.; MIGLIORANZA, E. Germinação de sementes de café submetidas a diferentes tempos de hidratação em água. In: SIMPÓSIO DE PESQUISA DOS CAFÉS DO BRASIL, 4, 2005, Londrina. Anais... Brasília, DF: Embrapa Café, 2005. 1 CD. 
MIRANDA, J. M. et al. Estudos de alguns fatores que influenciam a duração da viabilidade de sementes de café. Revista Brasileira de Sementes, Brasília, v.15, n.2, p.215-220, 1993.

MOTTA, C. A. P., Recuperação da viabilidade de sementes de café após tratamentos de hidratação e desidratação. Ciência e Agrotecnologia, Lavras, v.25, p.1142-1149, 2001.

NAKAGAWA, J. Testes de vigor baseados no desempenho das plântulas. In: KRZYZANOWSKI, F.C. et al. Vigor de sementes: conceitos e testes. Londrina: ABRATES, 1999. cap.2, p1-21.

SILVEIRA, V.D. Micologia. 5. ed. Rio de Janeiro: Âmbito Cultural, 1995.336p.

SINGH, K. et al. An illustrated manual on Identification of some Seed-borne Aspergilli, Fusara, Penicilia and their Mycotoxins. Denmark: Danish Government Institute of Seed Pathology for Developing Countries Ryvangs, 1992. $133 p$.

SGUAREZI, C.N. et al. Influência das condições de armazenamento na qualidade fisiológica e sanitária das sementes de café (Coffea arabica L.). Revista Brasileira de Armazenamento, Viçosa, n.4, p.16-25, 2002.

SGUAREZI, C.N. et al. Avaliação de tratamentos prégerminativos para melhorar o desempenho de sementes de café (Coffea arabica L.). I-Condicionamento osmótico. Revista Brasileira de Sementes, Brasília, v.23, n.2, p.152-161, 2001 a.

SGUAREZI, C.N. et al. Avaliação de tratamentos prégerminativos para melhorar o desempenho de sementes de café (Coffea arabica L.). II-Processo de umidificação. Revista Brasileira de Sementes, Brasília, v.23, n.2, p.162-170, $2001 b$. 